\title{
Associations of physical performance and physical activity with mental well-being in middle-aged women
}

Dmitriy Bondarev ${ }^{1 *}$ D, Sarianna Sipilä ${ }^{1}$, Taija Finni², Urho M. Kujala ${ }^{3}$ Pauliina Aukee ${ }^{4}$, Vuokko Kovanen ${ }^{3}$, Eija K. Laakkonen ${ }^{1}$ and Katja Kokko'

\begin{abstract}
Background: To investigate whether physical performance is independently of physical activity (PA) associated with positive and negative dimensions of mental well-being in middle-aged women.

Methods: Data were drawn from the Estrogenic Regulation of Muscle Apoptosis (ERMA) study in which women 47 to 55 years were randomly selected from the Finnish National Registry. They $(n=909)$ participated in measurements of physical performance (handgrip force, knee extension force, vertical jumping height, maximal walking speed, and six-minute walking distance). Both mental well-being (the Centre for Epidemiologic Studies Depression Scale, the International Positive and Negative Affect Schedule Short Form and the Satisfaction with Life Scale) and PA were self-reported. Associations between variables were analysed using multivariate linear regression modelling adjusted for body height, fat mass \%, menopausal status and symptoms, marital status, parity, employment status, selfreported mental disorders, and use of psycholeptics and psychoanaleptics. PA was then entered into a separate model to explore its role in the associations.
\end{abstract}

Results: In the adjusted models, significant positive associations of six-minute walking distance with positive affectivity ( $B=0.12, p=0.002)$ and life satisfaction ( $B=0.15, p=0.033)$ were observed. No significant associations were observed between physical performance and depressive symptoms or negative affectivity. PA was positively associated with positive affectivity and life satisfaction and negatively with depressive symptoms across all the physical performance variables.

Conclusions: Of the physical performance dimensions, aerobic component was associated with positive mental well-being independently of PA level. In relation to other physical performance components, the results point to the benefits of physical activity for mental well-being.

Keywords: Depressive symptoms, Life satisfaction, Negative affectivity, Positive affectivity, Physical performance, Middle-age women, Aerobic capacity

\footnotetext{
*Correspondence: dima-bondarev@gmx.de

'Gerontology Research Center and Faculty of Sport and Health Sciences, University of Jyväskylä, P.O. Box 35 (viv 152), Fl-40014 Jyväskylä, Finland

Full list of author information is available at the end of the article
}

(c) The Author(s). 2021 Open Access This article is licensed under a Creative Commons Attribution 4.0 International License, which permits use, sharing, adaptation, distribution and reproduction in any medium or format, as long as you give appropriate credit to the original author(s) and the source, provide a link to the Creative Commons licence, and indicate if changes were made. The images or other third party material in this article are included in the article's Creative Commons licence, unless indicated otherwise in a credit line to the material. If material is not included in the article's Creative Commons licence and your intended use is not permitted by statutory regulation or exceeds the permitted use, you will need to obtain permission directly from the copyright holder. To view a copy of this licence, visit http://creativecommons.org/licenses/by/4.0/ The Creative Commons Public Domain Dedication waiver (http://creativecommons.org/publicdomain/zero/1.0/) applies to the data made available in this article, unless otherwise stated in a credit line to the data. 


\section{Background}

Mental well-being is a multidimensional construct with positive dimensions, such as general satisfaction with life and positive affectivity, and with negative dimensions such as mental distress and negative affectivity [1]. Higher mental well-being is associated with better health outcomes (e.g., fewer incidents of coronary heart diseases) and longer life expectancy [2,3]. Although mental wellbeing has been shown to be relatively stable across the adult years [4], midlife is considered a life transition point at which the cumulative influence of several factors, including menopausal-related hormonal changes or personal life events, may influence mental well-being $[5,6]$.

Age-associated decline in physical functioning that results in mobility limitations or disabilities among older people [7] may also be related to low mental well-being [8]. It has been shown that women who transitioned through perimenopause to postmenopause had a decline in muscle strength and muscle power on average by $2-$ $3 \%$, which may suggest that the decline in physical functioning accelerates already during midlife $[9,10]$. However, the physical performance of more physically active middle-aged women is greater than that of less physically active peers [11]. Since physical activity in middleaged women is beneficially associated with both positive mental well-being $[12,13]$ and greater physical performance, mental well-being may also be higher in better physically performing middle-aged women.

Physical performance and physical activity have a close functional relationship. Despite considerable individual differences in the response to regular physical activity, in general, the higher the intensity and amount of physical activity, the better the physical performance [14]. However, the possible influence of physical performance and physical activity on mental well-being may stem from different sources. Physical activity may be linked to wellbeing through neurobiological (e.g., release of opioids), psychological (e.g., sense of mastery or emotions) or behavioural mechanisms (e.g., health-related behaviour) $[15,16]$. Physical performance, in turn, acts as a mechanism in the relationship between physical activity and well-being [17] and may partially be a product of genetics or the amount of physical activity or other life-style choices. A meta-analysis of intervention studies on the link between physical activity and mental well-being showed that, at advanced ages, an improvement in physical performance induced by exercise interventions is related to improved well-being [18]. However, it has not been fully verified whether the level of physical performance plays a role in mental well-being. As middle adulthood in women coincides with a spontaneous reduction in physical activity that may be related to menopauseassociated hormonal deficiency [19] and key personal life events [5], it would be useful to further investigate the independent role of physical performance in mental well-being for middle-aged women.

Thus, the aim of this study was to investigate whether physical performance - independent of physical activity - is associated with positive and negative dimensions of mental well-being, utilising a comprehensive set of physical performance measurements.

\section{Methods}

Study design and participants

This study is a part of the Estrogenic Regulation of Muscle Apoptosis (ERMA) study. The ERMA study is a population-based cohort study which consists of the data from women aged 47 to 55 years living in the city of Jyväskylä or neighbouring municipalities in Finland. A detailed description of participant recruitment has been reported earlier [20]. Briefly, an invitation to participate in the study was sent to 6878 women randomly selected from the Finnish National Registry (Fig. 1). Exclusion criteria were a self-reported body mass index (BMI) greater than $35 \mathrm{~kg} / \mathrm{m}^{2}$, pregnant women or lactating, medical conditions affecting ovarian function (e.g., bilateral ovariectomy, estrogen-containing hormonal preparations), or chronic diseases or medications that may significantly affect muscle function. Among the included participants, $2 \%$ reported use of psycholeptics and $7 \%$ use of psychoanaleptics medication. Their health status was followed by study physician and they were allowed to participate in the study.

Eligible participants $(n=1627)$ were assessed fasting blood samples in our laboratory and filled in the health screen questionnaire $(n=1393)$. Participants who had reported serious or unclear health conditions were examined by a physician to ensure safe participation in the physical performance measurements. The present analysis concerns women who performed at least one of the physical performance measurements acceptably and completed at least one mental well-being measurement $(n=909)$.

All participants gave their written informed consent. The study protocol followed good clinical and scientific practice and the Declaration of Helsinki and was approved by the Ethics Committee of the Central Finland Health Care District (K-SSHP Dnro 8 U/2014).

\section{Physical performance}

A detailed description of the measurement of physical performance - handgrip and knee extension force, low body muscle power, maximum walking speed and aerobic capacity - has been given earlier [11]. Briefly, handgrip and maximal isometric knee extension forces were measured in Newtons. Handgrip force was measured on the side of the dominant hand with the participant seated in an adjustable dynamometer chair (Good 
Finnish population register:

$82 \%$ of 47 - to 55 -yr.-old women living in the Jyväskylä area $(n=6878)$ were sent a postal invitation to participate

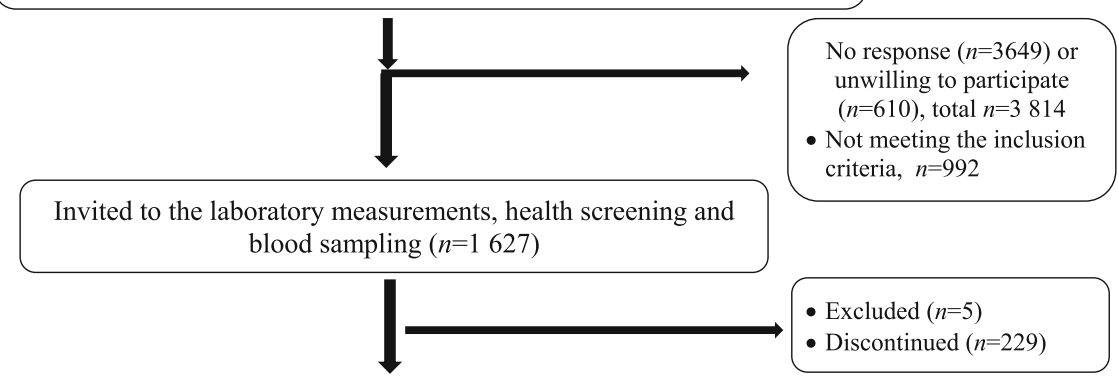

Menopausal status measurements based on hormonal status and menstrual diary $(n=1)$

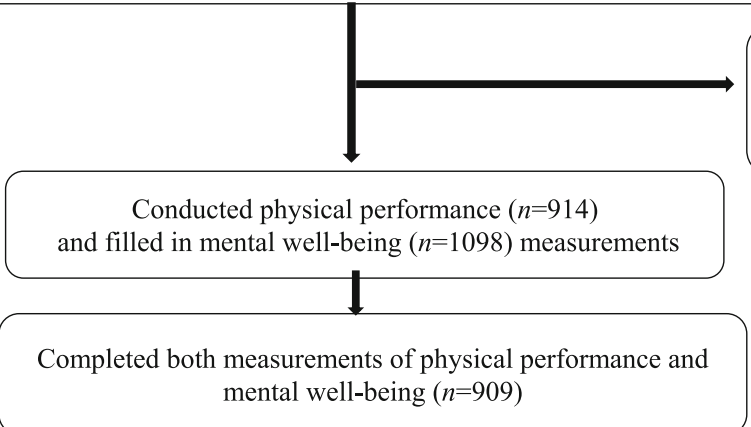

Fig. 1 Enrolment of study participants

Strength, Metitur, Palokka, Finland) with elbow flexed at $90^{\circ}$. The participants were instructed to squeeze the handle for $2-3 \mathrm{~s}$ to produce maximum force. Knee extension force was measured with the same dynamometer chair with a knee angle set at $60^{\circ}$ from full extension. Participants were encouraged to extend the knee to produce maximal force.

Lower body muscle power was assessed by a vertical jump on a contact mat. Vertical jumping height was calculated in cm from flight time $(t):\left(\mathrm{g} \times t^{2}\right) \div 8 \times 100$.

In all the above tests, three to five maximal attempts were performed and the best performance was taken as the result.

Maximum walking speed was measured over $10 \mathrm{~m}$ with the instruction to walk "as fast as possible" and timed with photocells. The fastest time of two trials, with self-selected rest of 30-60 s between trials, was taken as the result.

Aerobic capacity was assessed with the help of the sixminute walking test. The test was performed on a $20-\mathrm{m}$ indoor track, and participants were encouraged to complete as many laps as they could within $6 \mathrm{~min}$. The distance covered in meters was used in the analysis.

\section{Mental well-being}

Depressive symptoms were measured with the 20-item Center for Epidemiological Studies Depression Scale (CES-D [21]). Participants were asked to indicate how often they experienced each symptom over the past week. Each item was scored from $0=$ seldom or never to $3=$ almost all the time; a mean score for the 20 items was computed. Lower scores corresponded to lower depressive symptomatology.

The International Positive and Negative Affect Schedule Short Form (I-PANAS-SF [22]) was used to measure positive and negative affectivity. This inventory comprises five positive affect adjectives and five negative affect adjectives. Participants rated each of these adjectives on a scale from $1=$ does not describe me to $5=$ describes me very well. Average scores ranging from 1 to 5 were computed for each affective subscale, with lower scores indicating a lower degree to experience positive or negative affectivity.

Life satisfaction was measured with the 5-item Satisfaction with Life Scale which intended to evaluate global cognitive judgments of one's life satisfaction [23]. Participants indicated the degree to which they agree or disagree with each of the 5 items on a scale ranging from $1=$ strongly disagree to $7=$ strongly agree. The mean score of the scale for the five items was computed, with lower scores corresponding to lower satisfaction with life.

\section{Physical activity}

Level of leisure physical activity was measured on a seven-point scale assessing physical activity patterns 
from household duties, leisure-time physical activity to competitive sports. The PA questionnaire has been described previously and has been validated in middleaged women [24]. Briefly, the response categories were: $1=$ inactive, $2=$ light activity 1 to 2 times per week, $3=$ light activity several times per week, $4=$ moderate activity 1 to 2 times per week, $5=$ moderate activity several times per week, $6=$ high activity several times per week, and $7=$ competitive sports and related training several times per week. The seven response categories were recoded to form three levels of PA: low (categories 1 and 2), medium (3 and 4), and high (5 and 7), that were used as a variable for the analysis.

\section{Background and adjusted variables}

Age was calculated from date of birth to the date of the first laboratory visit. Level of education was measured with a single question and responces were grouped as primary (primary school), secondary (secondary school) and tertiary (applied science or bachelor's degree, nurse training, master's degree or $\mathrm{PhD}$ ).

Body height was measured in meters by a stadiometer. Body mass was measured in kilograms with a digital scale with the participant wearing undergarments only.

Body fat was measured in percentage of body weight with a multifrequency bioelectrical impedance analyser (InBodyTM 720; Biospace, Seoul, Korea).

Menopausal status was measured based on monthly self-reported bleeding patterns and serum follicle stimulating hormone (FSH) concentrations according to the Stages of Reproductive Aging Workshop (STRAW) recommendations [25]. FSH measurements were conducted from fasting serum samples which were collected between 8:00 and 10:00 AM. For women in their menstrual cycle, the collection was performed during cycle days 1 to 5. For serum separation, a centrifugation of the blood samples was applied for $10 \mathrm{~min}$ at $2.200 \mathrm{x}$ g. Systemic FSH was measured using solid-phase, enzyme-labeled chemiluminescent competitive immunoassay (IMMULITE 2000 XPi, Siemens Healthcare Diagnostics, UK).

A detailed description of the categorisation by menopausal status has been reported previously [20]. Briefly, participants' menopausal status was characterised as premenopausal if they reported a regular menstrual cycle and had FSH values < $17 \mathrm{IU} / \mathrm{L}(\mathrm{M}=7.72, \mathrm{SD}=3.50)$; as early perimenopausal if they had FSH values from 17 to below $25 \mathrm{IU} / \mathrm{L}$ or if they reported an irregular menstrual cycle and had FSH values >9.5 IU/L $(\mathrm{M}=16.76, \mathrm{SD}=$ 4.77); as late perimenopausal if they had FSH values in the range more or equal to 25 to $30 \mathrm{IU} / \mathrm{L}$ or if they reported occasional menstrual bleeding during the past 3 months and had FSH values $>30 \mathrm{IU} / \mathrm{L}(\mathrm{M}=44.90, \mathrm{SD}=$ 19.96); and as postmenopausal if they reported no menstrual bleeding during the past 6 months and had FSH values $>30 \mathrm{IU} / \mathrm{L}$ or reported no menstrual bleeding during the past 3 months and had FSH values> $39 \mathrm{IU} / \mathrm{L}$ $(\mathrm{M}=82.48, \mathrm{SD}=28.82)$.

Menopausal symptoms were assessed with a structured questionnaire to determine whether participants had any symptoms associated with menopause, such as: sweating, hot flashes, sleeping problems, headache, joint pain, tiredness, mood swings, vaginal symptoms, urinary track problems, sexual problems, or any other symptoms. For the present analysis, responses were recoded into a dichotomous variable (menopausal symptoms/no menopausal symptoms).

Marital status was assessed with the one question and responses were grouped as single, married or living with a partner, or divorced, separated or widowed. Parity was grouped as nulliparous, one or two children, and three or more children. Employment status was dichotomised as employed (paid or self-employed) or not regularly employed (study, unemployed, occasional job or retired). A diagnosed mental disorder was self-reported as yes/ no. Information on the use of medications that could influence mental well-being (N05, psycholeptics and N06, psychoanaleptics) was self-reported and coded in accordance to the Anatomical Therapeutic Chemical Classification System [26]. The codes represent respective dichotomous variables - users or non-users.

\section{Data analysis}

Characteristics of the participants are shown as means and standard deviations or as percentages. Multiple regression analyses were employed to examine the association between the physical performance variables and dimensions of mental well-being. In model 1 , regression models were adjusted for body height, fat mass percentage, menopausal status and symptoms, marital status, parity, employment status, self-reported mental disorders, use of psycholeptics and psychoanaleptics. In model 2, physical activity was added. These variables, deemed theoretically important, were justified based on our previous study with ERMA participants on various associations between physical activity, physical performance measurements, and mental well-being [11, 12]. All analyses were performed with $\mathrm{R}$, version 3.3 .3 and the package sjmisc [27]. $P$-values $\leq 0.05$ were considered statistically significant. All categorical variables included in the adjustment were treated automatically as categorical variables in the regression analyses.

\section{Results}

The mean age of the participants was 51 (SD 2) years. More than half (56\%) had secondary education and $42 \%$ had a tertiary degree (Table 1 ). Women were evenly distributed by their menopausal status. Most participants reported having experienced menopausal symptoms and 
Table 1 Descriptive information on the participants

\begin{tabular}{|c|c|c|}
\hline Variables & Total $n$ & Mean (SD) or $n(\%)$ \\
\hline Age, years & 909 & $51.51(2.05)$ \\
\hline Education & 898 & \\
\hline Primary & & $17(2)$ \\
\hline Secondary & & $506(56)$ \\
\hline Tertiary & & $375(42)$ \\
\hline Body height, m & 908 & $1.62(0.06)$ \\
\hline Body mass, kg & 908 & $69.73(10.85)$ \\
\hline Body fat mass, $\%$ & 905 & $30.5(7.48)$ \\
\hline Menopausal status & 909 & \\
\hline Premenopausal & & $232(25)$ \\
\hline Early perimenopausal & & $182(21)$ \\
\hline Late perimenopausal & & $197(22)$ \\
\hline Postmenopausal & & $298(32)$ \\
\hline Menopausal symptom (yes) & 907 & $702(77)$ \\
\hline Marital status & 906 & \\
\hline Single & & $79(9)$ \\
\hline Married or registered partnership & & $687(76)$ \\
\hline Divorced, separated or widowed & & $140(15)$ \\
\hline Parity & 906 & \\
\hline Nulliparous & & $110(12)$ \\
\hline One or two & & $512(55)$ \\
\hline Three or more & & $284(33)$ \\
\hline Employment status & 909 & \\
\hline Employed & & $808(89)$ \\
\hline Not regularly employed & & $101(11)$ \\
\hline Self-reported mental disorders (yes) & 903 & $62(7)$ \\
\hline Users of psycholeptics (N05) & 908 & $17(2)$ \\
\hline Users of psychoanaleptics (N06) & 908 & $67(7)$ \\
\hline Physical activity level & 909 & \\
\hline Low & & $159(18)$ \\
\hline Medium & & $570(62)$ \\
\hline High & & $180(20)$ \\
\hline Depressive symptoms, mean (SD) & 908 & $0.46(0.37)$ \\
\hline Negative affect, mean (SD) & 907 & $1.54(0.50)$ \\
\hline Positive affect, mean (SD) & 908 & $3.78(0.62)$ \\
\hline Life satisfaction, mean (SD) & 908 & $5.24(1.07)$ \\
\hline Hand grip strength, $\mathrm{N}$ & 903 & $313.1(59.6)$ \\
\hline Knee extension strength, $\mathrm{N}$ & 786 & $462.3(94.6)$ \\
\hline Vertical jumping height, m & 813 & $0.19(0.04)$ \\
\hline Maximal walking speed $\left(\mathrm{ms}^{-1}\right)$ & 900 & $2.64(0.46)$ \\
\hline Six-minute walking distance (m) & 835 & $669.1(60.9)$ \\
\hline
\end{tabular}

Values given are $\mathrm{n}(\%)$ for variables without units of measurement and mean (SD) for variables with units of measurement were married or living in a registered partnership. More than half of the participants had one or two children and reported a medium level of physical activity. Nearly $90 \%$ were employed.

\section{Depressive symptoms and negative affectivity}

No significant associations between physical performance and depressive symptoms and negative affectivity were observed (Model 1, Tables 2 and 3). The results did not change after adding physical activity into the model (Model 2, Tables 2 and 3). However, physical activity showed a significant reverse association with depressive symptoms across all the physical performance predictors, indicating that, irrespective of physical performance, depressive symptoms were significantly lower in women with a self-reported medium or high physical activity level than in those with a low physical activity level. Physical activity was not significantly associated with negative affectivity.

\section{Life satisfaction and positive affectivity}

A significant positive association was observed between six-minute walking distance and life satisfaction (Model 1, Table 4). After adding physical activity into the model, this association remained significant (Model 2, Table 4). None of the other physical performance predictors were significantly associated with life satisfaction, although physical activity showed a significant positive association with life satisfaction for every physical performance predictor. This indicates that the physical performance of women with a medium or high physical activity level was also better than those with low physical activity.

Significant positive associations were observed between knee extension, vertical jumping height, maximal walking speed, six-minute walking distance and positive affectivity (Model 1, Table 5). When physical activity was added into the model, these associations were no longer significant, except for that between six-minute walking distance and positive affectivity (Model 2, Table 5). Similarly, with respect to life satisfaction, physical activity showed a significant positive association with positive affectivity across all the physical performance predictors. These results indicate that, independently, physical activity is significantly positively associated with positive affectivity. However, of the investigated physical performance predictors, only six-minute walking distance had an independent positive association with positive affectivity.

\section{Discussion}

The results showed that, among 47- to 55-year-old women, aerobic capacity (measured as six-minute walking distance) was, irrespective of physical activity, positively associated with life satisfaction and positive 
Table 2 Associations of physical performance predictors with depressive symptoms

\begin{tabular}{|c|c|c|c|c|c|c|}
\hline \multirow[t]{2}{*}{ Predictors } & \multicolumn{3}{|c|}{ Model 1} & \multicolumn{3}{|c|}{ Model 2} \\
\hline & $B$ & $\mathrm{Cl}$ & $p$ & $B$ & $\mathrm{Cl}$ & $p$ \\
\hline Hand grip & 0.03 & $-0.01-0.07$ & 0.138 & 0.03 & $-0.01-0.07$ & 0.124 \\
\hline PA (medium level) ${ }^{\mathrm{a}}$ & & & & -0.09 & $-0.15--0.03$ & 0.005 \\
\hline PA (high level) ${ }^{a}$ & & & & -0.14 & $-0.22--0.06$ & 0.001 \\
\hline Knee extension & -0.01 & $-0.03-0.02$ & 0.536 & 0.00 & $-0.03-0.03$ & 0.950 \\
\hline PA (medium level) ${ }^{a}$ & & & & -0.09 & $-0.16--0.02$ & 0.011 \\
\hline PA (high level) ${ }^{a}$ & & & & -0.16 & $-0.24--0.08$ & 0.001 \\
\hline Vertical jumping height & -0.16 & $-0.85-0.52$ & 0.639 & 0.02 & $-0.68-0.71$ & 0.960 \\
\hline PA (medium level) ${ }^{a}$ & & & & -0.11 & $-0.18--0.05$ & 0.001 \\
\hline PA (high level) ${ }^{a}$ & & & & -0.15 & $-0.24--0.07$ & $<0.001$ \\
\hline Maximal walking speed & 0.03 & $-0.02-0.08$ & 0.256 & 0.04 & $-0.02-0.09$ & 0.168 \\
\hline PA (medium level) ${ }^{a}$ & & & & -0.10 & $-0.16--0.03$ & 0.002 \\
\hline PA (high level) ${ }^{a}$ & & & & -0.14 & $-0.22--0.07$ & $<0.001$ \\
\hline Six-minute walking distance & 0.01 & $-0.04-0.05$ & 0.735 & 0.02 & $-0.03-0.07$ & 0.395 \\
\hline PA (medium level) $)^{\mathrm{a}}$ & & & & -0.08 & $-0.14--0.01$ & 0.021 \\
\hline PA (high level) ${ }^{a}$ & & & & -0.14 & $-0.22--0.06$ & 0.001 \\
\hline
\end{tabular}

Model 1 adjusted for body height, fat mass \%, menopausal status and symptoms, marital status, parity, employment status, self-reported mental disorders, use of psycholeptics, use of psychoanaleptics

Model $2=$ Model $1+$ physical activity

$B$ unstandardised coefficients, $P A$ physical activity

Values in bold indicate statistically significant results

${ }^{a}$ reference category is low physical activity level

Table 3 Associations of physical performance predictors with negative affectivity

\begin{tabular}{|c|c|c|c|c|c|c|}
\hline \multirow[t]{2}{*}{ Predictors } & \multicolumn{3}{|c|}{ Model 1} & \multicolumn{3}{|c|}{ Model 2} \\
\hline & $B$ & $\mathrm{Cl}$ & $p$ & $B$ & $\mathrm{Cl}$ & $p$ \\
\hline Hand grip & -0.00 & $-0.06-0.05$ & 0.902 & -0.00 & $-0.06-0.05$ & 0.903 \\
\hline PA (medium level) ${ }^{\mathrm{a}}$ & & & & -0.01 & $-0.10-0.08$ & 0.870 \\
\hline PA (high level) ${ }^{a}$ & & & & 0.01 & $-0.10-0.12$ & 0.857 \\
\hline Knee extension & -0.03 & $-0.06-0.01$ & 0.148 & -0.03 & $-0.07-0.01$ & 0.133 \\
\hline PA (medium level) ${ }^{\mathrm{a}}$ & & & & -0.02 & $-0.11-0.08$ & 0.764 \\
\hline PA (high level) ${ }^{a}$ & & & & 0.00 & $-0.12-0.12$ & 0.867 \\
\hline Vertical jumping height & -0.58 & $-1.55-0.40$ & 0.245 & -0.64 & $-1.64-0.35$ & 0.207 \\
\hline PA (medium level) ${ }^{a}$ & & & & -0.01 & $-0.10-0.09$ & 0.898 \\
\hline PA (high level) ${ }^{a}$ & & & & 0.02 & $-0.09-0.14$ & 0.693 \\
\hline Maximal walking speed & -0.01 & $-0.09-0.06$ & 0.745 & -0.01 & $-0.09-0.06$ & 0.733 \\
\hline PA (medium level) ${ }^{a}$ & & & & 0.00 & $-0.09-0.09$ & 0.980 \\
\hline PA (high level) ${ }^{a}$ & & & & 0.02 & $-0.09-0.13$ & 0.765 \\
\hline Six-minute walking distance & -0.00 & $-0.07-0.06$ & 0.920 & -0.00 & $-0.07-0.06$ & 0.899 \\
\hline PA (medium level) ${ }^{a}$ & & & & -0.00 & $-0.10-0.09$ & 0.966 \\
\hline PA (high level) ${ }^{a}$ & & & & 0.01 & $-0.11-0.13$ & 0.876 \\
\hline
\end{tabular}

Model 1 adjusted for height, fat mass \%, menopausal status and symptoms, marital status, parity, employment status, self-reported mental disorders, use of psycholeptics, use of psychoanaleptics

Model 2 = Model $1+$ Physical activity

$B$ unstandardised coefficients, $P A$ physical activity

Values in bold indicate statistically significant results

areference category is low physical activity level 
Table 4 Associations of physical performance predictors with life satisfaction

\begin{tabular}{|c|c|c|c|c|c|c|}
\hline \multirow[t]{2}{*}{ Predictors } & \multicolumn{3}{|c|}{ Model 1} & \multicolumn{3}{|c|}{ Model 2} \\
\hline & B & $\mathrm{Cl}$ & $p$ & B & $\mathrm{Cl}$ & $p$ \\
\hline Hand grip & -0.03 & $-0.14-0.09$ & 0.664 & -0.03 & $-0.14-0.08$ & 0.615 \\
\hline PA (medium level) ${ }^{\mathrm{a}}$ & & & & 0.36 & $0.18-0.54$ & $<0.001$ \\
\hline PA (high level) ${ }^{a}$ & & & & 0.51 & $0.29-0.73$ & $<0.001$ \\
\hline Knee extension & 0.06 & $-0.02-0.13$ & 0.149 & 0.03 & $-0.05-0.11$ & 0.449 \\
\hline PA (medium level) ${ }^{a}$ & & & & 0.37 & $0.18-0.57$ & $<0.001$ \\
\hline PA (high level) ${ }^{a}$ & & & & 0.58 & $0.34-0.81$ & $<0.001$ \\
\hline Vertical jumping height & 0.57 & $-1.48-2.62$ & 0.587 & -0.12 & $-2.19-1.95$ & 0.909 \\
\hline PA (medium level) ${ }^{\mathrm{a}}$ & & & & 0.40 & $0.21-0.59$ & $<0.001$ \\
\hline PA (high level) ${ }^{a}$ & & & & 0.57 & $0.33-0.81$ & $<0.001$ \\
\hline Maximal walking speed & 0.10 & $-0.05-0.25$ & 0.194 & 0.08 & $-0.07-0.23$ & 0.312 \\
\hline PA (medium level) ${ }^{a}$ & & & & 0.36 & $0.18-0.54$ & $<0.001$ \\
\hline PA (high level) ${ }^{a}$ & & & & 0.52 & $0.29-0.74$ & $<0.001$ \\
\hline Six-minute walking distance & 0.19 & $0.05-0.32$ & 0.006 & 0.15 & $0.01-0.28$ & 0.033 \\
\hline PA (medium level) ${ }^{a}$ & & & & 0.28 & $0.09-0.47$ & 0.004 \\
\hline PA (high level) ${ }^{a}$ & & & & 0.47 & $0.23-0.71$ & $<0.001$ \\
\hline
\end{tabular}

Model 1 adjusted for height, fat mass \%, menopausal status and symptoms, marital status, parity, employment status, self-reported mental disorders, use of psycholeptics, use of psychoanaleptics

Model 2 = Model $1+$ Physical activity

$B$ unstandardised coefficients, $P A$ physical activity

Values in bold indicate statistically significant results

areference category is low physical activity level

Table 5 Associations of physical performance predictors with positive affectivity

\begin{tabular}{|c|c|c|c|c|c|c|}
\hline \multirow[t]{2}{*}{ Predictors } & \multicolumn{3}{|c|}{ Model 1} & \multicolumn{3}{|c|}{ Model 2} \\
\hline & $B$ & $\mathrm{Cl}$ & $p$ & $B$ & $\mathrm{Cl}$ & $p$ \\
\hline Hand grip & -0.01 & $-0.08-0.06$ & 0.849 & -0.01 & $-0.08-0.06$ & 0.793 \\
\hline PA (medium level) ${ }^{\mathrm{a}}$ & & & & 0.19 & $0.08-0.29$ & 0.001 \\
\hline PA (high level) ${ }^{a}$ & & & & 0.45 & $0.32-0.58$ & $<0.001$ \\
\hline Knee extension & 0.05 & $0.00-0.09$ & 0.041 & 0.02 & $-0.02-0.07$ & 0.366 \\
\hline PA (medium level) ${ }^{a}$ & & & & 0.15 & $0.04-0.27$ & 0.007 \\
\hline PA (high level) ${ }^{a}$ & & & & 0.41 & $0.28-0.55$ & $<0.001$ \\
\hline Vertical jumping height & 1.23 & $0.03-2.44$ & 0.045 & 0.51 & $-0.69-1.71$ & 0.403 \\
\hline PA (medium level) ${ }^{\mathrm{a}}$ & & & & 0.19 & $0.08-0.30$ & 0.001 \\
\hline PA (high level) ${ }^{a}$ & & & & 0.44 & $0.30-0.58$ & $<0.001$ \\
\hline Maximal walking speed & 0.09 & $0.00-0.18$ & 0.046 & 0.07 & $-0.02-0.16$ & 0.105 \\
\hline PA (medium level) ${ }^{a}$ & & & & 0.20 & $0.09-0.30$ & $<0.001$ \\
\hline PA (high level) ${ }^{a}$ & & & & 0.46 & $0.33-0.60$ & $<0.001$ \\
\hline Six-minute walking distance & 0.16 & $0.08-0.24$ & $<0.001$ & 0.12 & $0.04-0.20$ & 0.002 \\
\hline PA (medium level) ${ }^{a}$ & & & & 0.14 & $0.03-0.26$ & 0.011 \\
\hline PA (high level) ${ }^{a}$ & & & & 0.41 & $0.28-0.55$ & $<0.001$ \\
\hline
\end{tabular}

Model 1 adjusted for height, fat mass \%, menopausal status and symptoms, marital status, parity, employment status, self-reported mental disorders, use of psycholeptics, use of psychoanaleptics

Model 2 = Model 1+ Physical activity

$B$, unstandardised coefficients, $P A$ physical activity

Values in bold indicate statistically significant results

${ }^{a}$ reference category is low physical activity level 
affectivity. Physical activity in turn showed a stronger association with positive mental well-being than that of physical performance assessed by muscle strength, muscle power and maximal walking speed. Physical performance was not associated with negative dimensions of mental well-being such as negative affectivity or depressive symptoms, whereas physical activity was associated with fewer depressive symptoms.

Although modest, the association of aerobic capacity with positive mental well-being was not attenuated when physical activity was included in the model. Although the association between physical activity and positive affect has been well demonstrated [28], studies have predominantly assessed short-term effects of physical activity on positive affect (e.g. after exercise interventions). In addition, physical performance level, which may play a role in affective responses to exercise [29], has often been overlooked in this relationship. Our study extends these results and provides evidence that in addition to regular leisure physical activity, aerobic capacity may have unique importance for positive mental well-being.

The fitness hypothesis holds that the beneficial effect of physical activity is due to gains in fitness [17]. It may be that, through regular physical activity, positive affective states accumulate over time [30] in parallel with improvements in aerobic physical fitness. Mechanistically, one biological pathway via which aerobic capacity may enhance positive affect is the greater oxidative capacity that results from improved mitochondrial function and angiogenesis, which in turn increases microvascular density in the brain [31]. This prompts speculation regarding structural and functional changes in the brain related specifically to mood state. However, due to the correlational study design, the opposite or bidirectional association is equally possible. Women with higher positive affect may be more physically active and hence fitter or their greater aerobic physical fitness may enable them to be more physically active.

Our results partially support those of the FLAMENCO study (the Fitness League Against MENopause Cost), which found a positive association between aerobic fitness and positive affect among perimenopausal women [32]. However, the same study also reported significant associations of self-reported muscle strength and speedagility with positive and negative affect and depressive symptoms. This discrepancy could be explained by differences in the assessment methods. In comparison with performance-based measurements, self-reported physical performance may be less sensitive in identifying minor deficits in functioning because middle-aged participants may not yet recognize them.

Midlife represents a specific phase of life during which a reduction in physical activity can be expected [5, 19]. This may cause (or be a consequence of) vulnerability in mental well-being. Among middle-aged women, higher physical activity was associated with higher positive wellbeing and lower depressive symptomatology [12]. Thus, greater aerobic capacity may be viewed as a unique resource that helps to attenuate the effects of a decline in physical activity on mental well-being in middle-aged women.

Although aerobic capacity can be relatively quickly improved [33], it must be acknowledged that some individuals may have a genetic predisposition to high aerobic capacity [14]. In addition, genotype may also modify the association between physical activity and improvement in aerobic capacity [34]. This, however, raises the practical question of how to deal with individuals who have low aerobic capacity. Are there inherent reasons (such as an underlying medical condition) for low cardiorespiratory capacity or is it caused by modifiable factors (e.g., life-style choices) and correctable? Thus, our finding on the independent association of aerobic capacity and positive mental well-being, although promising for middle-aged women, merits further research (including other types of measurement of aerobic capacity) to confirm the direction of the association and identify the factors underlying it. Furthermore, it would be important to investigate, preferably using longitudinal data, competing models, where, for example, physical performance and physical activity were, alternatively, set as mediators.

In our study, other components of physical performance (low body muscle strength, muscle power, walking speed) were also associated with positive affectivity. However, these associations were attenuated after adjustment for physical activity. This result points to the role of physical activity in this association and may support the "mastery hypothesis", according to which participation in physical activity may instil a sense of coherence and mastery resulting in increased positive affect $[35,36]$. This sense of mastery may not necessarily require a high level of muscle strength or power, and it may also be a function of other socio-psychological factors of participation in physical activity [37].

Our study showed no associations between any of the physical performance measurements and either negative affect or depressive symptoms. Several systematic reviews, although not focusing on the concomitant role of physical activity, have shown that cardiorespiratory fitness associates with lower incidents of depression [38, 39]. We found that physical activity, not physical performance, was associated with fewer depressive symptoms. One recent study of women aged 45-69 years living in Singapore found that those with high depressive symptoms (CES-D $\geq 16)$ had lower handgrip strength and lower body muscle power (5 repeated chair stands) than those with no depressive symptoms [40]. Interestingly, the above-mentioned analysis was adjusted for 
physical activity, and hence may suggest that handgrip strength and lower extremity functioning are factors independent of a high level of depressive symptoms. We analysed the association between depressive symptoms and handgrip strength as continuous variables rather than the association high and low muscle strength groups. It is possible that the associations between the groups, which were formed by categorising the participants into two levels of depressive symptoms and two levels of handgrip strength, may have resulted in overestimation of the results.

The results indicate that the link between physical performance and depressive symptoms found in our participants may be explained by level of physical activity. If so, this suggests that the women in our study potentially derived social or psychological benefit from participation in physical activity even in the absence of a gain in muscle strength, power or walking speed. In support of this argument, previous studies have found that better physical health predicted physical activity in men but not in women, for whom the social context of physical activity may provide additional psychological benefit [41, 42]. However, the absence of sex differences in the performance vs. social benefits of physical activity has also been reported [43].

The main limitation of this study is the correlational analysis, which precluded us from drawing conclusions on causality. Another limitation is that physical activity was self-reported, and thus the number of highly physically active participants may have been overestimated [44]. Our study is limited to participants with BMI $<35$ $\mathrm{kg} / \mathrm{m} 2$. Obesity and menopausal factors may synergistically influence physical performance among obese middle-aged women [45]. Although, we controlled our analysis for menopausal status and fat mass percentage, our results may not be generalized to severely obese individuals.

Among the strengths of this study is the comprehensive measurement of physical performance in a large cohort study. Previous studies investigating the associations between physical performance and mental wellbeing outcomes have predominantly assessed aerobic fitness to the relative neglect of other components of physical performance. Moreover, they have largely explored the association between physical performance and depressive symptoms (i.e., the negative dimension of mental well-being). Our study extends previous research by including both positive as well as negative dimensions of mental well-being. We were also able to include confounders known to have associations with mental wellbeing or physical performance in middle-aged women, including menopausal status, which was carefully categorised using menstrual diaries and hormonal analysis following the STRAW+10 criteria, self-reported mental disorders and use of medications. Our study participants represent a homogeneous group of relatively healthy, non-severely obese women within a narrow age range, thereby reducing the possible influence of unobservable variables while also reducing the results to be generalised to more heterogeneous populations.

\section{Conclusions}

This study, conducted among middle-aged women, revealed a positive association between aerobic capacity and positive mental well-being independently of the level of physical activity, although when physical activity was included in the analysis, the associations of the other components of physical performance studied (i.e., low body muscle strength, muscle power, walking speed) with positive affectivity were attenuated. Moreover, physical performance was not associated with the negative dimensions of mental well-being; instead, physical activity showed a stronger negative association with depressive symptoms. Thus, given the important role of physical activity for mental well-being found in this study, aerobic capacity may be considered a unique resource for positive mental well-being. However, the results warrant additional research to confirm the direction of the association and identify the factors underlying it.

\section{Abbreviations}

PA: Physical Activity; FSH: Follicle Stimulating Hormone; ERMA: Estrogenic Regulation of Muscle Apoptosis; BMI: Body Mass Index; CES-D: Center for Epidemiological Studies Depression Scale; I-PANAS-SF: International Positive and Negative Affect Schedule Short Form; STRAW: Stages of Reproductive Aging Workshop; FLAMENCO: the Fitness League Against MENopause Cost

\section{Acknowledgments}

The authors thank all the ERMA study participants and the staff members of the Gerontology Research Center and Faculty of Sport and Health Sciences who helped with the study.

\section{Authors' contributions}

$\mathrm{DB}$, the corresponding author, compiled, analysed and interpreted the data and drafted the original manuscript. SS, TF, UMK, PA, EKL, VK, KK designed, conceived and supervised the entire study; SS, VK, and EL planned the ERMA study and obtained funding, PA was responsible for the gynaecological data, UMK for the medical examination and KK for the psychological measurements. All authors participated in the revision of the manuscript and read and approved the final version.

\section{Funding}

This study was supported by funding from the European Union's Horizon 2020 research and innovation programme under a Marie Sklodowska-Curie grant agreement (PANINI No 675003 to Sarianna Sipilä), the Academy of Finland (grant 275323 to Vuokko Kovanen, grant 309504 to Eija K. Laakkonen) and the Ministry of Education and Culture of Finland (OKM/49/626/2017, OKM/72/626/2018, OKM/92/626/2019 to Katja Kokko).

Availability of data and materials

The dataset generated and analysed during the current study is not publicly available due to being confidential but is available from the PI of the project (Eija K. Laakkonen) on reasonable request. 


\section{Declarations}

\section{Ethics approval and consent to participate}

The study protocol followed good clinical and scientific practice and the Declaration of Helsinki and was approved by the Ethics Committee of the Central Finland Health Care District (K-SSHP Dnro 8 U/2014). All participants provided a written informed consent.

\section{Consent for publication}

Not applicable.

\section{Competing interests}

None.

\section{Author details}

Gerontology Research Center and Faculty of Sport and Health Sciences, University of Jyväskylä, P.O. Box 35 (viv 152), Fl-40014 Jyväskylä, Finland. ${ }^{2}$ Neuromuscular Research Center, Faculty of Sport and Health Sciences, University of Jyvaskyla, P.O. Box 35 (viv), Fl-40014 Jyväskylä, Finland. ${ }^{3}$ Faculty of Sport and Health Sciences, University of Jyväskylä, P.O. Box 35 (viv), Fl-40014 Jyväskylä, Finland. Department of Obstetrics and Gynecology, Pelvic Floor Research and Therapy Unit, Central Finland Central Hospital, Hoitajantie 3, Fl-40620 Jyväskylä, Finland.

\section{Received: 8 July 2020 Accepted: 9 July 2021}

\section{Published online: 23 July 2021}

\section{References}

1. Diener E, Lucas RE, Oishi S. Subjective well-being: the science of happiness and life satisfaction. Handbook Positive Psychol. 2002;2:63-73.

2. Diener $\mathrm{E}$, Chan MY. Happy people live longer: subjective well-being contributes to health and longevity. Appl Psychol. 2011;3(1):1-43. https:// doi.org/10.1111/j.1758-0854.2010.01045.x.

3. Kushlev K, Heintzelman SJ, Lutes LD, Wirtz D, Kanippayoor JM, Leitner D, et al. Does happiness improve health? Evidence from a randomized controlled trial. Psychol Sci. 2020;31(7):807-21. https://doi.org/10.1177/ 0956797620919673.

4. Kokko K, Korkalainen A, Lyyra A-L, Feldt T. Structure and continuity of wellbeing in mid-adulthood: a longitudinal study. J Happiness Stud. 2013;14(1): 99-114. https://doi.org/10.1007/s10902-011-9318-y.

5. Brown W, Heesch KC, Miller YD. Life events and changing physical activity patterns in women at different life stages. Ann Behav Med. 2009;37(3):294 305. https://doi.org/10.1007/s12160-009-9099-2.

6. Shea AK, Sohel N, Gilsing A, Mayhew AJ, Griffith LE, Raina P. Depression, hormone therapy, and the menopausal transition among women aged 45 to 64 years using Canadian longitudinal study on aging baseline data. Menopause. 2020;27(7):763-70. https://doi.org/10.1097/GME.0000000000001 540.

7. Rantanen T, Guralnik JM, Foley D, Masaki K, Leveille S, Curb JD, et al. Midlife hand grip strength as a predictor of old age disability. JAMA. 1999;281(6): 558-60. https://doi.org/10.1001/jama.281.6.558

8. Gale CR, Cooper C, Deary IJ, Sayer AA. Psychological well-being and incident frailty in men and women: the English longitudinal study of ageing. Psychol Med. 2014;44(4):697-706. https://doi.org/10.1017/S0033291 713001384.

9. da Câmara SMA, Zunzunegui MV, Pirkle C, Moreira MA, Maciel ÁCC. Menopausal status and physical performance in middle aged women: a cross-sectional community-based study in Northeast Brazil. PLoS One. 2015: 10(3):e0119480. https://doi.org/10.1371/journal.pone.0119480.

10. Bondarev D, Finni T, Kokko K, Kujala UM, Aukee P, Kovanen V, et al. Physical performance during the menopausal transition and the role of physical activity. J Gerontol. 2020. https://doi.org/10.1093/gerona/glaa292.

11. Bondarev D, Laakkonen EK, Finni T, Kokko K, Kujala UM, Aukee P, et al. Physical performance in relation to menopause status and physical activity. Menopause. 2018:25(12):1432-41. https://doi.org/10.1097/GME. 0000000000001137.

12. Bondarev D, Sipilä S, Finni T, Kujala UM, Aukee P, Laakkonen EK, et al. The role of physical activity in the link between menopausal status and mental well-being. Menopause. 2020;27(4):398-409. https://doi.org/10.1097/GME. 0000000000001490 .
13. Elavsky S, McAuley E. Physical activity, symptoms, esteem, and life satisfaction during menopause. Maturitas. 2005:52(3-4):374-85. https://doi. org/10.1016/j.maturitas.2004.07.014.

14. Blair SN, Cheng Y, Holder JS. Is physical activity or physical fitness more important in defining health benefits? Med Sci Sports Exerc. 2001; 33(Supplement):S379-99. https://doi.org/10.1097/00005768-20010600100007.

15. Bragina I, Voelcker-Rehage C. The exercise effect on psychological wellbeing in older adults - a systematic review of longitudinal studies. German J Exerc Sport Res. 2018;48(3):323-33. https://doi.org/10.1007/s12662-018-052 5-0

16. Lubans D, Richards J, Hillman C, Faulkner G, Beauchamp M, Nilsson M, et al. Physical activity for cognitive and mental health in youth: a systematic review of mechanisms. Pediatrics. 2016;138(3):e20161642. https://doi.org/1 0.1542/peds.2016-1642.

17. Bouchard CE, Shephard RJ, Stephens TE. Physical activity, fitness, and health: the model and key concepts. Toronto: Human Kinetics Publishers; 1994

18. Netz Y, Wu M-J, Becker BJ, Tenenbaum G. Physical activity and psychological well-being in advanced age: a meta-analysis of intervention studies. Psychol Aging. 2005;20(2):272-84. https://doi.org/10.1037/08827974.20.2.272.

19. Melanson EL, Lyden K, Gibbons E, Gavin KM, Wolfe P, Wierman ME, et al Influence of estradiol status on physical activity in premenopausal women. Med Sci Sports Exerc. 2018;50:1704-9. https://doi.org/10.1249/mss. 0000000000001598

20. Kovanen V, Aukee P, Kokko K, Finni T, Tarkka IM, Tammelin T, et al. Design and protocol of estrogenic regulation of muscle apoptosis (ERMA) study with 47 to 55-year-old women's cohort: novel results show menopauserelated differences in blood count. Menopause. 2018;25(9):1020-32. https:// doi.org/10.1097/GME.0000000000001117.

21. Radloff LS. The CES-D scale: a self-report depression scale for research in the general population. Appl Psychol Meas. 1977;1(3):385-401. https://doi.org/1 $0.1177 / 014662167700100306$

22. Thompson ER. Development and validation of an internationally reliable short-form of the positive and negative affect schedule (PANAS). J CrossCult Psychol. 2007:38(2):227-42. https://doi.org/10.1177/0022022106297301.

23. Diener E, Emmons RA, Larsen RJ, Griffin S. The satisfaction with life scale. J Pers Assess. 1985:49(1):71-5. https://doi.org/10.1207/s15327752jpa4901_13.

24. Hyvärinen M, Sipilä S, Kulmala J, Hakonen H, Tammelin T, Kujala UM, et al. Validity and reliability of a single question for leisure time physical activity assessment in middle-aged women. Journal of aging and physical activity 1-11. 2019;28(2):231-41. https://doi.org/10.1123/japa.2019-0093.

25. Harlow SD, Gass M, Hall JE, Lobo R, Maki P, Rebar RW, et al. Executive summary of the stages of reproductive aging workshop +10 : addressing the unfinished agenda of staging reproductive aging. Menopause (New York, Ny). 2012;19(4):387-95. https://doi.org/10.1097/ gme.0b013e31824d8f40.

26. World Health Organization Collaborating Centre for Drug Statistical Methodology (2017) Anatomical therapeutic chemical (ATC) classification system ATC classification index with DDDs.

27. Lüdecke D. Sjmisc: data and variable transformation functions. J Open Source Softw. 2018;3:754

28. Ekkekakis $\mathrm{P}$, Brand $\mathrm{R}$. Affective responses to and automatic affective valuations of physical activity: fifty years of progress on the seminal question in exercise psychology. Psychol Sport Exerc. 2019:42:130-7. https://doi.org/10.1016/j.psychsport.2018.12.018.

29. Petruzzello SJ, Hall EE, Ekkekakis P. Regional brain activation as a biological marker of affective responsivity to acute exercise: influence of fitness. Psychophysiology. 2001;38(1):99-106. https://doi.org/10.1111/1469-8986.381 0099

30. Kishida M, Elavsky S. Daily physical activity enhances resilient resources for symptom management in middle-aged women. Health Psychol. 2015;34(7): 756-64. https://doi.org/10.1037/hea0000190

31. Voss MW, Weng TB, Burzynska AZ, Wong CN, Cooke GE, Clark R, et al. Fitness, but not physical activity, is related to functional integrity of brain networks associated with aging. Neuroimage. 2016;131:113-25. https://doi. org/10.1016/j.neuroimage.2015.10.044

32. Aparicio VA, Marín-Jiménez N, Coll-Risco I de la Flor-Alemany M، BaenaGarcía L, Acosta-Manzano P, et al. Doctor, ask your perimenopausal patient about her physical fitness; association of self-reported physical fitness with cardiometabolic and mental health in perimenopausal women: the FLAM 
ENCO project. Menopause. 2019;26(10):1146-53. https://doi.org/10.1097/ GME.0000000000001384.

33. Murias $J M$, Kowalchuk JM, Paterson DH. Mechanisms for increases in $\mathrm{V}$ O2max with endurance training in older and young women. Med Sci Sports Exerc. 2010;42(10):1891-8. https://doi.org/10.1249/MSS.0b013e3181dd0bba.

34. Sisson SB, Katzmarzyk PT, Earnest CP, Bouchard C, Blair SN, Church TS. Volume of exercise and fitness non-response in sedentary, post-menopausal women. Med Sci Sports Exerc. 2009;41(3):539-45. https://doi.org/10.1249/ MSS.0b013e3181896c4e.

35. Brown J. Staying fit and staying well: physical fitness as a moderator of life stress. J Pers Soc Psychol. 1991;60(4):555-61. https://doi.org/10.1037/0022-3 514.60.4.555.

36. Kekäläinen T, Kokko K, Sipilä S, Walker S. Effects of a 9-month resistance training intervention on quality of life, sense of coherence, and depressive symptoms in older adults: randomized controlled trial. Qual Life Res. 2018; 27(2):455-65. https://doi.org/10.1007/s11136-017-1733-z.

37. Netz Y. Type of activity and fitness benefits as moderators of the effect of physical activity on affect in advanced age: a review. Eur Rev Aging Phys Act. 2009;6(1):19-27. https://doi.org/10.1007/s11556-009-0043-z.

38. Kandola A, Ashdown-Franks G, Stubbs B, Osborn D, Hayes J. The association between cardiorespiratory fitness and the incidence of common mental health disorders: a systematic review and meta-analysis. J Affect Disord. 2019;257:748-57. https://doi.org/10.1016/j.jad.2019.07.088.

39. Papasavvas T, Bonow RO, Alhashemi M, Micklewright D. Depression symptom severity and cardiorespiratory fitness in healthy and depressed adults: a systematic review and meta-analysis. Sports Med. 2016;46(2):21930. https://doi.org/10.1007/s40279-015-0409-5.

40. Ganasarajah S, Poromaa IS, Thu WP, Kramer MS, Logan S, Cauley JA, et al. Objective measures of physical performance associated with depression and/or anxiety in midlife Singaporean women. Menopause. 2019;26(9): 1045-51. https://doi.org/10.1097/GME.0000000000001355.

41. Chipperfield JG, Newall NE, Chuchmach LP, Swift AU, Haynes TL. Differential determinants of men's and women's everyday physical activity in later life. Gerontol Ser B Psychol Sci Soc Sci. 2008;63(4):S211-8. https://doi.org/10.1 093/geronb/63.4.S211.

42. Teychenne M, Ball K, Salmon J. Associations between physical activity and depressive symptoms in women. Int J Behav Nutr Phys Act. 2008;5(1):27. https://doi.org/10.1186/1479-5868-5-27.

43. Grunseit A, Richards J, Merom D. Running on a high: parkrun and personal well-being. BMC Public Health. 2018;18(1):59. https://doi.org/10.1186/s12889017-4620-1.

44. Cerin E, Cain KL, Oyeyemi AL, Owen N, Conway TL, Cochrane T, et al. Correlates of agreement between accelerometry and self-reported physical activity. Med Sci Sports Exerc. 2016;48(6):1075-84. https://doi.org/10.1249/ MSS.0000000000000870.

45. Karvinen $\mathrm{S}$, Jergenson MJ, Hyvärinen $M$, Aukee $P$, Tammelin $T$, Sipilä S, et al. Menopausal status and physical activity are independently associated with cardiovascular risk factors of healthy middle-aged women: cross-sectional and longitudinal evidence. Front Endocrinol (Lausanne). 2019;10:589. https:// doi.org/10.3389/fendo.2019.00589.

\section{Publisher's Note}

Springer Nature remains neutral with regard to jurisdictional claims in published maps and institutional affiliations.

Ready to submit your research? Choose BMC and benefit from:

- fast, convenient online submission

- thorough peer review by experienced researchers in your field

- rapid publication on acceptance

- support for research data, including large and complex data types

- gold Open Access which fosters wider collaboration and increased citations

- maximum visibility for your research: over $100 \mathrm{M}$ website views per year

At $\mathrm{BMC}$, research is always in progress.

Learn more biomedcentral.com/submissions 